\title{
Modern trends in medical education: A critical appraisal
}

\section{Bapat SK}

Professor and Head of Department, Department of Pharmacology, Kathmandu Medical College, Sinamangal, Nepal

$\mathrm{L}^{2}$ ately, lot of interest has been generated in the different aspects of medical education. The whole issue is about the teaching patterns in the medical institutions, possibly because of the dissatisfaction amongst the medical educationists about the conventional type of teaching curricula and methods. As a result, various new ways of curriculum planning have been suggested like--PBL, integrated teaching, microteaching, OSPE, OSCE.

An attempt is being made here to review the conventional teaching and the modern teaching patterns and to point out the pros and cons of both and try to find some such method which is practicable, reliable, acceptable and most importantly, suitable and is required for the respective country's needs.

Education is defined as: - the art of acquiring, retaining, reproducing and utilising knowledge when required. Thus, education has to be viewed as an art, not a science.

Logically then, medical education is the art of acquiring, and retaining knowledge of medical subjects so that it could be utilized for the healing of the patient when required. It is important to use the word "healing" which encompasses a wider horizon rather than the more commonly used "treatment".

What is knowledge? Is it merely information? In the perspective of medical education, various skills are also equally, if not more, important and these skills are taught in every subject right from the day a student enters the medical college. Knowledge is defined as "expertise and skills acquired by a person through information and experience" ${ }^{1}$.

By and large, medical education has been imparted in the form of various subjects which were initially designated as -clinical and non-clinical. Later on, they were named as pre- i.e. before, para (along with) and clinical. It was thought that basic knowledge of subjects like Anatomy, Physiology and Biochemistry was essential before the students reach the clinical side.
Pharmacology, Pathology, Community Medicine and Forensic Medicine were considered to be suitable to be taught along with the clinical subjects.

Later on, especially in Nepal, the non-clinical subjects were named as Basic medical subjects which include all the pre and para medical subjects. A student, who is admitted in year1, is suddenly exposed to 7 subjects and computer and clinical orientation. During this period the student is given some clinical orientation by the Community Medicine Department.

The above has perhaps resulted because it was thought that much more time should be given to the clinical subjects and the basic subjects were not that important.

Many other deficiencies were supposed to exist in the teaching pattern of basic medical subjects-

1. all the subjects were taught in water tight compartments without having any co-ordination with each other.

2. much stress was given on the didactic lectures which involved a mere transfer of information from the teacher to the taught, thus making the medical education a purely passive phenomenon.

3. it did not involve any participation from the students and they were not stimulated to acquire knowledge and skills.

The above deficiencies are genuine and possibly to overcome these, modern trends were developed where integrated teaching in basic medical subjects was started, first of all, in U.K. Integrated teaching involves the teaching of various subjects in a co-ordinate fashion, so that the boundaries of the subjects are abolished and now on the teaching is system wise rather than subject wise. Integrated teaching is a method of teaching that interrelates or unifies subjects frequently taught in separate departments, the subjects are presented together

Correspondence

Dr. Sudhir K Bapat

Department of Pharmacology

Kathmandu Medical College, Sinamangal, Kathmandu

E-mail: sudhir768@rediffmail.com 
as a meaningful whole. Integration may be horizontal or vertical, horizontal functions between parallel subjects like Anatomy, Physiology and Biochemistry whereas vertical functions between subjects taught in different phases of education. It must be noted that the medical/MBBS courses of all the Universities of Nepal are community oriented and system based as per the syllabus.

Further, a new method of imparting education was suggested which is named as -- Problem based learning (PBL) -- many institutions in India and Nepal are trying to start it. The basic concept of PBL is very good where the student actively participates in the learning process. PBL is a term used within education that encourages students to learn through the structured exploration of a problem. Teaching is not by lectures but by putting forward practical problems and asking the students to find out the answers themselves and later on discussing in groups.

PBL was first practiced in countries where the medical students are more mature and have already passed several years studying related subjects and have been exposed to PBL, before entering the medical institutions. Many medical schools of developing countries have now taken up PBL. In India and Nepal, the students are admitted in first year only after I.Sc. and are not mature enough and suddenly are exposed to 7 subjects about which they have absolutely no idea.

Thus, there are many pit falls, problems and questions:

1. is it suitable for a student who is admitted to 1 year and is completely raw.

2. is it really required and necessary for the students in India and Nepal?

Moreover, PBL is a highly evolved form of teaching which requires a large number of sincere, devoted and learned faculty members and students who are of that standard. In an atmosphere, both in India and Nepal, where medical education is privatised and commercialised and where the main aim of the students is to somehow pass and get the degree of MBBS, PBL seems to be too high sounding. A large number of medical institutions are started in India and Nepal and there is a shortage of teachers in basic medical subjects. Moreover, the basic medical subjects are looked down upon and it is the opinion of not only students and parents but some of the clinical teachers also, at least in India, if not in Nepal, that the real teaching is done in clinical subjects and there is no point in paying much attention to basic medical subjects.

PBL is already in practice in clinical subjects. The students are posted in different wards where they are exposed to a number of patients and each patient is a subject of PBL. Every practicing clinician is facing PBL every day in the form of patients. Major period of students stay in a medical college is spent in wards where PBL is automatically practiced; it may not be called as PBL.

It is in the basic medical subjects that PBL is being implemented and some institutions have already introduced it. There are tall claims that the students exposed to PBL are highly satisfied. Naturally, those will be satisfied in whatever way they are taught. There is no control study where a comparison could be made. Moreover, it was shocking to observe that the students in these institutions did not have the basic knowledge of any subject. Various examples could be cited. On the top of it, it is understood that no student has ever failed in any of the basic medical subjects. Are the students so brilliant or are the teachers so efficient or is the PBL so effective?

Next is the question of teaching aids. The use of OHP, transparencies and power point is highly advocated. The dictum

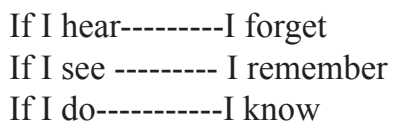

is very correct and visual aids are very useful especially in Anatomy and Pathology. But the whole problem arose when the teaching became totally dependent upon on these methods. The advantage of these aids to the teacher is that he / she no longer needs to study and remember the topic, just project the written material and read from it. There is no interaction with the students, no eye to eye contact, the teacher is merely reading from the projected material in the dark lecture room.

The students have been repeatedly asked whether they like the chalk and board or visual aids. Unanimously, students were in favour of chalk and board teaching with, of course, some visual aids. But a total dependence on visual aids was condemned by all. Some of the students even went to the extent of remarking that the teachers start reading from the projected material or written notes, as if they are reading a newspaper. Most of the students at the back sleep leave the class or are busy in something else.

Even in a didactic lecture, student participation is possible if the teacher interacts eye to eye, asks questions in between and permits the students to ask questions during the lecture. What is required is that a limited use of visual aids should be done and a total dependence avoided. After all, teaching is an art and not 
everyone can be a good teacher but at the same time no teacher is born as a good teacher. One has to inculcate the art of teaching and then someone will be excellent, someone very good, someone good but none will be bad. But total dependence on visual aids or even written notes would certainly brand a teacher as bad. It has to be borne in mind that teaching is an art not a science and hence the criticism that didactic type of lectures is a passive form of teaching stands more true for teaching which is totally dependent upon visual aids or / and written notes.

Lastly, the methods of assessment. Is it necessary to assess the knowledge gained and the skills attained by the student and if it is, how to assess. Some of the modern teachers advocate a complete abolition of examinations. Once the student is admitted, he passes out on the basis of his / her day to day performance. This is extreme and in all probabilities, it is agreed by most of the educationists that some way of assessment at every step is necessary.

The question is -assessment of what and how? Knowledge, skills, aptitude?

Knowledge is not merely information; it is information and experience and ability to utilise it.

The conventional methods of assessment -theory paper, viva voce and practical are criticised, the main objection being that these methods are very subjective that much depends upon the examiner and in order to make it purely objective, many methods of assessment have been suggested like-- objectively structured practical examination (OSPE) and objectively structured clinical examination (OSCE). In OSPE, same 5-6 questions are put forward to all the students and the examiner is not supposed to go beyond those questions. Anyone from the department comes and listens to the answers to the fixed questions and allots marks. This can also become subjective. As a matter of fact, no teacher should be required for such examination; even a laboratory boy could assess if he is told the answers to those questions, or even a computer could be programmed to assess the students and this would be a totally objective method. The biggest flaw in this type of assessment is that, if by chance, some good student is not able to answer those very questions but he/ she has read the subject very well, he / she may fail or vice versa if a very bad student, per chance, is able to answer those questions only, but he knows nothing else in the subject, he / she can pass.

Pattern of theory papers is completely changed in integrated teaching, instead of theory examinations in different subjects, a paper consists of one particular system and questions pertaining to all the subjects are there. Student has to pass in the paper as a whole. The biggest flaw in such type is that some students may totally omit one or two subjects and compensate in others.

Why should the assessment be objective, it must be understood that medical subjects cannot be mathematical and a student appearing in any subject has to be assessed as a whole, not in tit bits. Viva voce is the best form of assessment, where an examiner is able to extract out knowledge from the student by asking simple questions to start with and gradually raising the standard of the questions, thus helping him. The main objection for subjective type of assessment is that examiners may be prejudiced and a uniform standard may not be maintained. Examiners are taken to be like cruel animals bent upon failing the students. Even if some examiners are prejudiced, they are to help the student rather than harming him. No examiner is interested in failing a student, on the contrary, many students are passed on the basis of viva voce. Then student is to be assessed as a whole, not only knowledge but also personality, communication skill, way of presentation, attire, attitude, behaviour, performance throughout the year and also extracurricular activities like sports - all are judged by an experienced examiner within a couple of minutes. No student can ever complain that he deserved to pass but was failed deliberately by the examiner. If there is one who complains, he is the poorest and he knows this but wants to pass by deliberately accusing the examiner.

Thus, it appears that the conventional methods of assessment including are quite suitable for medical students in India and Nepal, at least.

\section{Conclusion and Suggestions}

The conventional pattern of medical education appears to be quite satisfactory; however, some modern trends are necessary to be adopted.

A complete integration in teaching all the basic medical subjects should be introduced meaning that the teaching should not be subject wise but system wise. The examinations should not be integrated, these should remain subject wise. Viva voce must be given more importance.

Teaching aids are necessary but a total dependence on them should be avoided.

PBL is not suitable under the present circumstances; however, if it has to be started, it should be started first in clinical subjects and later on in basic medical subjects and that also after the students have passed first year. 
Various other models could be suggested:

1. Only Anatomy, Physiology and Biochemistry should be taught in first year after completion of which other basic medical subjects should be taught for one year.

2. Clinical subjects should be started in second year simultaneously with Pathology, Pharmacology, Micro-biology, Community medicine and Forensic medicine and continued till $7^{\text {th }}$ semester after which two semesters should be exclusively devoted to Medicine, Surgery and Paediatrics.
3. Pathology, Pharmacology, Community medicine and Micro-biology should be started in $3^{\text {rd }}$ year and continued till 7 th semester.

\section{References}

1. Oxford university press. Oxford educational dictionary. UK: Oxford university press; 2008. 